H I G H L I G H T S

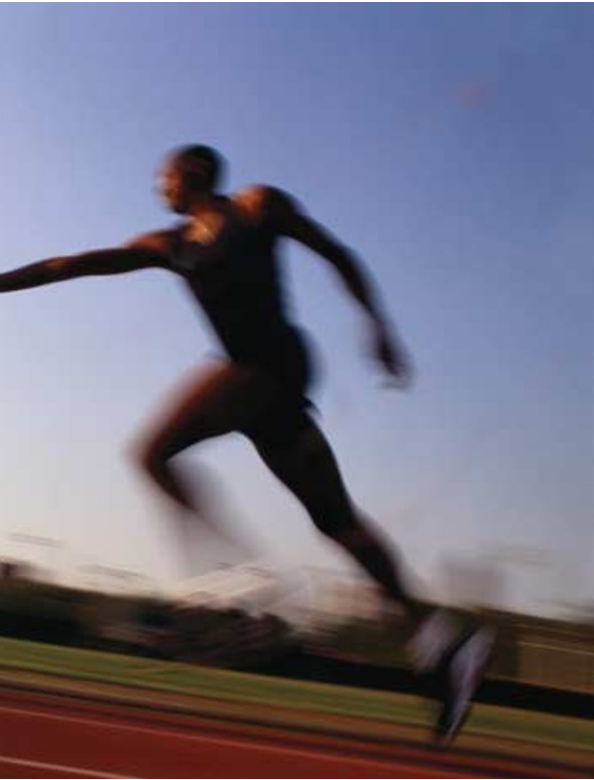

is required for the biogenesis of complex, $\beta$-barrel outer membrane proteins, but not for the biogenesis of relatively simple proteins.

Mas37 forms part of a complex that is devoid of Tom proteins and the authors called this complex SAM, because of its role in the sorting and assembly of outer mitochondrial membrane proteins. They found that mitochondria in which Mas37 has been disrupted accumulate non-assembled Tom 40 precursors.
However, by contrast, they showed that disrupting the Tom proteins that target the Tom 40 precursor does not result in the accumulation of these precursors. This shows that the TOM machinery is needed for initial import before SAM can function.

In the final part of their study, Meisinger and colleagues showed that blocking the general import pore of endogenous TOM greatly impaired the formation of the Tom 40 assembly intermediate I, which, again, indicates that TOM functions before SAM. This work has therefore changed our view of organellar protein sorting. It now seems that the TOM complex, which was previously thought to sort and assemble proteins, “...is not sufficient for the correct integration of outer membrane proteins with a complicated topology, and instead transfers precursor proteins to the SAM complex".

Rachel Smallidge

\section{0) References and links} ORIGINAL RESEARCH PAPER Wiedemann, N. et al. Machinery for protein sorting and assembly in the mitochondrial outer membrane. Nature $\mathbf{4 2 4}$ 565-571 (2003)

FURTHER PEADING Neupert W. \& Brunner, M. The protein import motor of mitochondria. Nature Rev. Mol. Cell Biol. 3, 555-565 (2002) WEB SITE

Nikolaus Pfanner's laboratory: http://www.biochemie.uni-freiburg.de/ pfanner/pfanner.htm

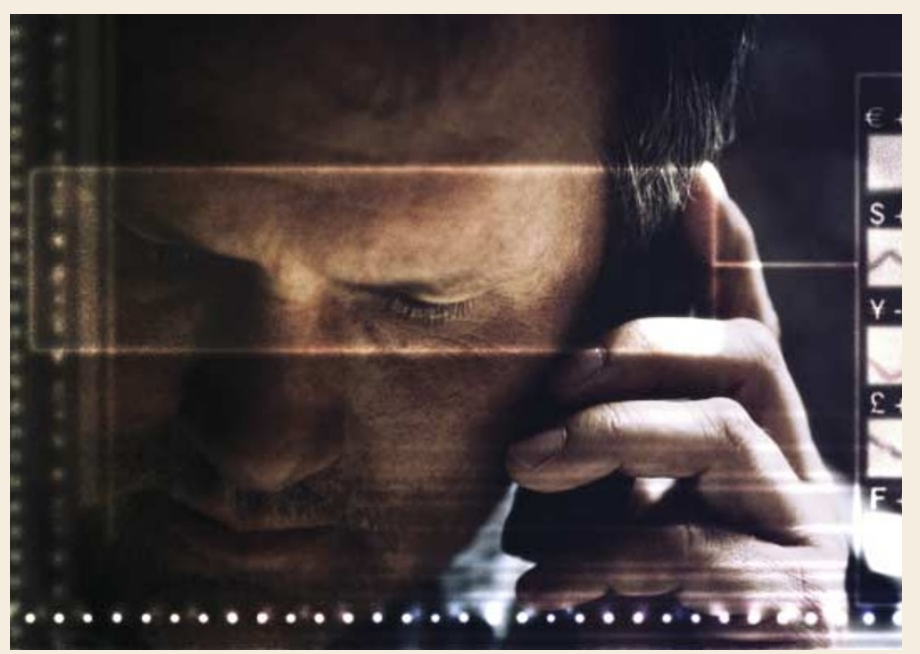

experimental system, and to further investigate the molecules and mechanisms of nuclear reprogramming. And, eventually, it might become possible to directly reprogramme human cells for cell-replacement therapy. Arianne Heinrichs
(9) References and links ORIGINAL RESEARCH PAPER Byrne, J. A. et al. Nuclei of adult mammalian somatic cells are directly reprogrammed to oct- 4 stem cell gene expression. Curr. Biol. 13, 1206-1213 (2003) WEB SITE

John B. Gurdon's laboratory:

http://www.welc.cam.ac.uk/groups/ gurdon.html

\section{IN BRIEF}

\section{NEURODEGENERATION}

Ubiquitin-mediated sequestration of normal cellular proteins into polyglutamine aggregates.

Donaldson, K. M. et al. Proc. Natt Acad. Sci. USA 100, 8892-8897 (2003)

In many neurodegenerative diseases, ubiquitin (Ub)-positive protein aggregates are present in affected neurons. But how these Ub-positive protein aggregates are formed is unclear. Donaldson et al. now show that two Ub-binding proteins, Atx-3 and $\mathrm{p} 62 /$ Sequestosome-1, which form aggregates in affected neurons, require the functional Ub-binding motifs for localization into aggregates. This recruitment, through $\mathrm{Ub}$, could contribute to the pathogenesis of neurodegenerative diseases.

\section{APOPTOSIS}

Induction of TNF receptor I-mediated apoptosis via two sequential signaling complexes.

Micheau, O. \& Tschopp, J. Cell 114, 181-190 (2003)

Signalling by the TNF-receptor I (TNFR1) can either promote cell survival or cause apoptosis. How the cell decides between the two pathways can now be explained, as TNFR1-induced apoptosis requires the formation of two sequential complexes. First, complex I forms, which comprises TNFR1, the adaptor TRADD, the kinase RIP1, and TRAF2, and it signals activation of nuclear factor (NF)- $\kappa B$. Unless NF- $\kappa B$ activation induces FLIP $_{L}$ - which inhibits the caspase- 8 - procaspases- 8 and -10 are recruited to form complex II, and this results in apoptosis.

\section{CELL ADHESION}

Integrin-ECM interactions regulate cadherin-dependent cell adhesion and are required for convergent extension in Xenopus.

Marsden, M. \& DeSimone, D. W. Curr. Biol. 13, 1182-1191 (2003)

Convergent extension is a fundamental developmental process that underlies cell and tissue movements in morphogenesis. This paper sheds light on the underlying molecular mechanisms, by showing that fibronectin-integrin interactions are essential for cell intercalation behaviour and axial extension in Xenopus.

Integrin modulation of cadherin adhesion influences morphogenetic movements within local areas that are defined by the fibronectin extracellular matrix.

\section{NUCLEAR TRANSPORT}

RanGTP mediates nuclear pore complex assembly.

Walther, T. C. et al. Nature 424, 689-694 (2003)

The multi-talented GTPase Ran has roles in nuclear transport, spindle formation and nuclear-envelope assembly. Walther et al. now uncover details of another of its suspected functions - in nuclear pore complex (NPC) formation. RanGTP production targets a subset of nucleoporins to the chromatin by dissociating them from importin- $\beta$, promotes the association between nucleoporin sub-complexes and triggers NPC insertion into membranes. 